\section{Stress free oral medication in captive cervids}

\section{Garga M. Das ${ }^{1}$, Anupam Srivastavi ${ }^{1}$, Debashish Chakraborty $^{1}$, S.K. Gupta ${ }^{2}$ \& Parag Nigam ${ }^{3}$}

1,3 Wildlife Institute of India, P.O. Box \# 18, Chandrabani, Dehra Dun, Uttarakhand 248001, India

${ }^{2}$ Department of Veterinary Parasitology, CCS Harayana

Agricultural University, Hisar, Haryana 125004, India

Email: ${ }^{3}$ nigamp@ wii.gov.in (corresponding author)

Captive wild animals need medication on number of occasions ranging from illness to diet supplementation or for immobilization. Medication in such situations is either administered orally by mixing required drug/agent in feed (Andrea et al. 1994) or parenterally through hand held systems or remote drug delivery systems (Harthoorn 1973). These procedures have their own limitations as there is a practical difficulty in treating individuals owing to the risk from the animals to the handler, chances of injury/trauma due to struggling during physical capture for both the animal and the handler and most importantly animal developing stress. Animals under stress may respond differently and an exaggerated response can be detrimental to the animal and may lead to shock and even be fatal. Minimizing stress greatly increases the chance of successful management. The other challenge is in ensuring that if not all, at least majority of the animals receive required quantity of drug.

Oral medication in herd situations offers little control over individual drug dosage, quantity of drug consumed by the animal and depends greatly on social structure, animal dominance, drug palatability and acceptability. Parenteral delivery on the other hand involves placing the animals under undue stress during capture for direct delivery, while in remote delivery, the problem of stress coupled with individual animal identification persists as the same animal may receive drugs

Date of publication (online): 26 September 2009

Date of publication (print): 26 September 2009

ISSN $0974-7907$ (online) | 0974-7893 (print)

Editor: Jacob V. Cheeran

Manuscript details:

Ms \# 01897

Received 03 December 2007

Final received 15 April 2008

Finally accepted 26 May 2009

Citation: Das, G.M., A. Srivastav, D. Chakraborty, S.K.Gupta \& P. Nigam (2009). Stress free oral medication in captive cervids. Journal of Threatened Taxa 1(9): 495-496

Copyright: (C) Garga M.Das, Anupam Srivastav, Debashish Chakraborty S.K.Gupta \& Parag Nigam 2009. Creative Commons Attribution 3.0 Unported License. JoTT allows unrestricted use of this article in any medium for nonprofit purposes, reproduction and distribution by providing adequate credit to the authors and the source of publication.

Acknowledgement: The authors thank the Director, Wildlife Institute of India for financial and administrative support; the Chief Wildlife Warden, Haryana for according necessary permission to initiate the study; and the Dean, College of Veterinary Sciences, CCS HAU, Hisar for technical support during the study. Cooperation and support of the staff at Hisar Deer Park is acknowledged.

OPEN AGGESS | FREE DOWNLOAD

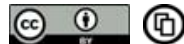

more than once while some animals may not receive medication at all. The chances of mortality in even healthy animals as a result of chemical/physical capture cannot be ruled out (Arnemo et al. 2006).

Animals in captivity are highly susceptible to both endo and ecto-parasitic infestations. This may further be compounded due to high stocking density, poor sanitation and hygiene practices and non-elimination of the infected individuals by natural processes operating in free ranging condition. In Indian conditions, helminthic infections are common amongst captive cervids and are often difficult to eliminate because of confinement and changed environmental conditions of the hosts (Acharjyo 2001).

Accordingly a novel method of habituating the animals to feed individually in separate containers and mixing required quantity of drug in the feed being given was tried out at Deer Park, Hissar. This was part of the study to assess the effect of anthelmintic on parasitic load in captive cheetal (Axis axis) and was conducted from November 2006 to January 2007.

\section{Study area}

The Deer Park is located on the outskirts of Hissar, $10 \mathrm{~km}$ on the Dhansu road and is spread over 16.99ha. A total of 30 Chital (Axis axis) along with nine Sambar (Rusa unicolor), 15 Black Buck (Antilope cervicapra), two Chinkara (Gazella bennettii) and one Nilgai (Boselaphus tragocamelus) are maintained in single large enclosure. The main vegetation of the Park and surrounding areas comprises of Prosopis spp., Acacia spp., Dalbergia spp., Ficus spp., and plantation of Eucalyptus spp. in addition to 2.42 ha. of fodder cultivation. The fodder cultivation plot is irrigated by an irrigation canal that passes through village and is utilized by livestock especially buffaloes and may contribute towards parasitic burden through drinking water. Animals are fed with the mixture of chopped green fodder and pelleted cattle feed during late mornings and only greens during evenings. The food is provided collectively to the animals in cemented mangers and is calculated at $15 \mathrm{~kg}$ of green fodder and $1.0 \mathrm{~kg}$ concentrate per day per cheetal.

\section{Methods}

Anthelmintic trial: The study included assessing parasitic load in animals prior to treatment, acclimatization of animals to individual feeding, anthelmintic treatment and assessment of parasitic load post treatment as referred by Shahardar (1995). The parasitic load was quantified in terms of eggs per gram (EPG) of faeces employing Modified Mc Master Technique (Coles 1986) to evaluate control measures against gastrointestinal helminths. A possible explanation to this may be supported by the findings of Schultz et al. (1993) who reported that previous contamination of pastures may be responsible for maintaining adequate reservoir of gastrointestinal nematodes in the enclosure that permits relatively rapid re-infection. Jansen (1985) suggested that effects of anthelmintic treatment are short lived unless pasture contamination is reduced. The procedure followed and the results achieved are discussed here.

Animal habituation/acclimatization and drug administration: The animals were habituated to feed in earthern pots having mouth diameter of $12.5 \mathrm{~cm}$ and a depth of $15 \mathrm{~cm}$ for a period of 10 days. To avoid single/dominant 
animal feeding from number of pots, they were placed at $1.5 \mathrm{~m}$ distance in two parallel rows in a zig zag fashion. All the containers were filled at one go before allowing the animals access to feed. The number of pots placed were equal to the number of cheetal in the enclosure. The approximate weight of animal for dose calculation was estimated to be $60 \mathrm{~kg}$ irrespective of sex and age. To ensure that all the animals get required quantum of drug, the weight estimation was on the higher side. Though drug dose was higher for does and fawn, this was used, as fenbendazole is reported to have wide safety margin (Roberson 1982; Bliss 2007).

A day prior to anthelmintic treatment the animals were fed only green fodder. The required measure of drug was mixed with limited quantity of grounded pelleted feed and jaggery and delivered in individual containers to the animal. Fenbendazole (Panacur ${ }^{\circledR}$ VET, Intervet, Pune, India) at $7.5 \mathrm{mg}$ / $\mathrm{kg}$ was provided per animal and repeated after 21 days. Feeding time was matched with daily feeding schedule. Majority of animals approached the pots together and consumed the drugconcentrate mixture fast. Once the drug was consumed, the animals were provided full concentrate ration along with green fodder. More than $90 \%$ of the total population consumed feed mixed with the drugs.

\section{Results}

Pre treatment parasitic load: Pre treatment faecal parasitic load was analyzed by sedimentation and floatation method (Coles 1986) and found to be $87.5 \%(21 / 24)$. The species wise parasite distribution included $43.80 \%$ Strongyles sp., $20.66 \%$ Strongyloides sp., 9.09\% each of Moniezia sp., Toxocara sp. and Trichuris sp. Additionally $8.26 \%$ of the samples revealed Coccidia oocyst. The EPG value prior to the treatment was $177 \pm 20.597$.

Post treatment parasitic load: The post treatment parasitic load showed significant reduction for all the parasitic species by day 11 with the overall EPG of faeces of 1.25 \pm 0.9 . Trichuris sp. however was eliminated by day 7 . Mild infection however existed on day 19 post treatment $(0.41 \pm 0.41)$ and may be attributed to re-exposure to infective larvae or the eggs. Parasitic ova could not be detected on day 21. Following second treatment on day 22, there was slight increase in the EPG $(0.41 \pm 0.41)$ on day 26 albeit at low levels. This may probably be attributed to parasite buildup within the enclosure and repeated exposure and infection.

\section{Discussion}

The observed parasitic prevalence of $87.5 \%$ in untreated animals is in consonance to the findings of Kashid et al. (2003) and Varadharajan \& Pythal (1999) who reported similar high parasitic prevalence of $96.31 \%$ and $76 \%$ respectively among ungulates in captivity and attributed it to high animal densities, repeated exposure to infective agent and consequently heavy contamination of enclosures. Fenbendazole was efficacious in reducing gastrointestinal burden in captive Cheeetal as reflected by faecal EPG levels which dropped from $177 \pm 20.597$ during pre treatment to $1.25 \pm 0.9,0.41 \pm 0.41$ on day 11 and 19 respectively post treatment. This is in consonance with Schultz et al. (1993) who reported that previous contamination of pastures may be responsible for maintaining adequate reservoir of gastrointestinal nematodes in the enclosure that permit relatively rapid re-infection. Jansen
(1985) suggested that effects of anthelmintic treatment are short lived unless pasture contamination is reduced. The reduction in parasitic load post treatment is in consonance to the findings of Shahardar et al. (1995) who, however, reported complete elimination of parasites by eighth day post fenbendazole treatment in Kashmiri stag.

\section{Conclusion}

It can be concluded that the drug delivery regimen adopted in the present study is efficacious without causing handling stress to the animals while ensuring that all animals receive equal dosage. The method can be used for selective administration of drugs for treating targeted individuals' as it is much better than the current practice of mixing medication in feed and then allowing the whole group to feed which results in both healthy and sick individuals receiving medication.

\section{References}

Acharjyo, L.N. (2001). Incidence of parasitic diseases among wild mammals and control in Indian zoo. Zoos' Print XVI(6): 1-5

Andrea. B., Mikolon., B.M. Walter, A.L. Jack. I.A. Gardner \& E.F. Lee (1994). Epidemiology and control of nematode parasites in collection of captive exotic ungulates. Journal of Zoo and Wildlife Medicine 25(4): 500-5 10

Arnemo, J.M., P. Ahlqvist, R. Andersen, F. Berntsen, G. Ericsson, J. Odden, S. Brunberg, P. Segerström \& J.E. Swenson (2006). Risk of capture-related mortality in large free-ranging mammals: experiences from Scandinavia. - Wildlife Biology 12: 109-113.

Bliss, D.H. (2007). Technical Bulletin: The control of Gastro-Intestinal Nematode Parasites of Hoofed Wildlife in North America. MidAmerica AG Research Verona, WI 53593. http:// w w w. midamerica a g e s e a r ch. net/documents / WIldlife\%20Monograph.pdf downloaded on 11, November 2007

Coles, E.H. (1986). Veterinary Clinical Pathology. $4^{\text {th }}$ Edition. W.B. Saunders Company. Philadelphia, pp.374-433.

Harthoorn, A.M. (1976). The chemical capture of animals- A guide to the chemical restraint of wild and captive animals. Bailliere Tindall, London.

Janssen, D.L. (1985). Efficacy of fenbendazole for endoparasite control in large herds of nondomestic ruminants. Journal of American Veterinary Medical Association. 187(11): 1189-90.

Kashid, K.P., G.B. Shrikhande, \& G.B. Bhole (2003). Incidence of gastrointestinal helminthes in captive wild animals at different locations. Zoos' Print Journal 18(3): 1053-1054.

Roberson, E.L. (1982). Antinematodal drugs. In: Booth, N.H. \& L.E. McDonald (eds.). Jones Veterinary Pharmacology and Therapeutics $5^{\text {th }} \mathrm{Ed}$. The Iowa State University Press, Ames, Iowa, 816pp.

Schultz, R.S., R.X. Barry, W.A. Forbes \& M.K. Johnson (1993). Efficacy of fenbendazole against gastrointestinal nematodes in White-tailed deer. Journal of Range Management 46: 240-244.

Shahardar, R.S., A.S. Mir, M. Mir, B.A. Pandit \& M.A. Ahmad (1995). Efficacy of fenbendazole against gastrointestinal nematodes of Kashmiri deer. Indian Veterinary Journal 72: 781-782.

Varadharajan, A. \& C. Pythal (1999). A preliminary investigation on the parasites of wild animals at the Zoological Garden, Thiruvanthapuram. Zoos' Print XIV: 3-12.

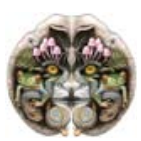

